\title{
Stress and Its Association with the Academic Performance of Undergraduate Fourth Year Medical Students at Universiti Kebangsaan Malaysia
}

\author{
Harlina H Siraj a , Salam A ${ }^{\mathrm{a}}$, Roslan $\mathrm{R}^{\mathrm{b}}$, Hasan NA ${ }^{\mathrm{b}}$, Jin $\mathrm{TH}^{\mathrm{b}}$, Othman MN \\ aedical Education Department, UKM Medical Centre, Malaysia \\ bSpecial Study Module (SSM) Research Group Students, Medical Education Department, UKM Medical Centre, \\ Malaysia
}

\begin{abstract}
Introduction: Student can be stressed due to different stressors such as academic, financial, health related or loss of close family member or friend, etc. Stress is the bodies' reaction both neurologically and physiologically to adapt to the new condition. Stress has a negative effect on the academic performance of the students. This study was aimed to explore the stress and stressors and also to determine the association between stress levels and the academic performances in terms of cumulative grade point average (CGPA) of undergraduate medical students. Methods: It was a cross-sectional study conducted among all 234 year-4 medical students of Universiti Kebangsaan Malaysia (UKM), session 2011-2012. Sample size comprised of 179 students after fulfilling all inclusion and exclusion criteria. A validated Medical Students' Stressor Questionnaire (MSSQ) was used to collect the data. Stress level and its association with CGPA of semester-1 examination were analysed. Results: Response rate was 76.49\%, where $72 \%$ were female and $69 \%$ resided in the hostel. Academic Related and Social-related Stressors caused for severe and high stress in $84 \%$ and $49 \%$ respondents respectively, with insignificant differences between gender and residency. Respondents with a high and severe stress level were observed to have higher CGPA. Conclusion: UKM medical students are highly resourceful to manage their stress well and thus denying the negative effect of stress towards their academic performance. Medical schools should train students exposing various personal and professional developmental activities that able to face the everyday challenges and manage stress well and thereby achieve better academic performance.
\end{abstract}

KEYWORDS: Stress, stressor, well-management, academic performance

\section{INTRODUCTION}

Academic performance is one of the most vital considerations among students in higher educational level. The academic performance can be illustrated by grade point average (GPA). Despite living in the millennium area where education is accessible to all, there are still some differences in performance among the students. Several studies identified internal and external factors associated with academic performance. Stress is one of the factors that has negative effect on the mastery of the academic curriculum. ${ }^{1}$

Corresponding author:

Assoc. Prof. Dr. Harlina Halizah Siraj Department of Medical Education, UKM Medical Centre Jalan Yaacob Latif, Bandar Tun Razak, 56000 Kuala Lumpur, MALAYSIA

Email: harlina@ppukm.ukm.edu.my
Stress is the body's nonspecific response mechanism towards demands or strains made on itself or the environment. ${ }^{2,3}$ It is a process by which we perceive and cope with environmental threats and challenges. ${ }^{4}$ Stress can be defined in Webster new world dictionary ${ }^{5}$ as "a condition typically characterized by symptoms of mental and physical tension or strain, as depression or hypertension, that can result from a reaction to a situation in which a person feels threatened, pressured, etc." An individual can be stressed in daily life in a different way, and stress can be viewed as the bodies' reaction both neurologically and physiologically to adapt to the new condition.6,7 A student can be stressed due to different reasons or stressors such as the academic, financial problem, health problem or loss of close family member or friend, etc. It is the persons' ability to face the everyday challenges which will determine whether he/she will be stressed or not. Stress in academic situation can have both positive and negative consequences. Stress can inhibit and suppress learning, which is called 'unfavourable stress' and is associated with inhibition of students' academic performance. ${ }^{8}$ Previous studies have reported a high prevalence of stress in medical students, ranging from $30 \%$ to $50 \% .{ }^{9,10}$ However, stress management training in medical school is needed to promote learning through coping of stress, which is called 'favourable stresses'. 


\section{MATERIALS AND METHODS}

This was a cross sectional, questionnaire survey, conducted on all 234 UKM medical students of year4, academic session 2011-2012. The survey period was from June 2011 to until May 2012. Participation in this study was voluntary and informed consent was taken from all participants to participate in this study. Students who did not give consent and those who filled the questionnaire incompletely were excluded from this study. As such, the sample size of this study comprised of 179 students.

To collect the data, medical students' stress questionnaire (MSSQ) was used, which was a validated instrument used to identify sources of stress. ${ }^{18}$ There were 40 items in MSSQ those represented the possible sources of stress in medical students and were grouped into six main domains. The six domains were: Academic Related Stressor (ARS), Intrapersonal and Interpersonal Related Stressor (IRS), Teaching and Learning Related Stressor (TLRS), Social Related Stressor (SRS), Drive and Desire Related Stressor (DRS), and Group Activities Related Stressor (GARS). The items under each stressor were measured using a rating scale $0-4$. Respondents were asked to rate each item as 0 for 'causing no stress at all', 1 for 'causing mild stress', 2 for 'causing moderate stress', 3 for 'causing high stress' and 4 for 'causing severe stress'. The reliability coefficients of the stressor groups ranged from 0.64 to 0.92 . The degree or level of stress were classified as: level 0-1.00 'causing nil to mild stress', level 1.01-2.00 'causing mild to moderate stress', level 2.01-3.00 'causing moderate to high stress' and level 3.01-4.00 'causing high to severe stress'. ${ }^{18}$ Before administering the questionnaire, a pilot test was conducted among 10 undergraduate students and finalized the questionnaire accordingly.

Academic performance of the medical students was measured by using the grades of all subjects in the first-semester examination of year-4. The cumulative grade point average (CGPA) of semester-1 examination was calculated in a 5.0 scale which was self-expressed by the students. Consent was also taken to disclose their CGPA of the semester-1 examination. All the data regarding CGPA were kept confidential. Data was analyzed using the statistical soft ware package for social sciences (SPSS) 17.0 version.

\section{RESULTS}

Out of 234 medical students, 186 students returned the questionnaire from which seven were incomplete and excluded. As such 179 respondents were included in this study giving a response rate of $76.49 \%$. One hundred and twenty nine students $(72 \%)$ were female and $50(28 \%)$ were male. Regarding the residency of the students, $123(69 \%)$ students were resided in the hostel while $56(31 \%)$ were resided out-campus (Table I).

Table II showed percentage of individual stressor domain. Majority of the respondents $(84 \%)$ were in severe stress, particularly with the academic related stressors, followed by $57 \%$ in group activity related stressor and 56\% in intrapersonal and interpersonal stressor domains. Social related stressors also cause high stress among the respondents (49\%).

Table III revealed the degree of stress level. A total of $16(8 \%)$ students showed to have a moderate level of stress while $93(53 \%)$ and $70(39 \%)$ have a high (level 2.01-3.00) and severe level (level 3.01-4.00) of stress respectively. It also showed the stress level between male and females.

Academic performance (Mean CGPA) of the respondents in terms of gender and residency has shown in Table IV. There is insignificant relationship between stress and academic performance both in terms of gender and residency. In total $76 \%$ respondents opined that stress motivates them for better academic performance while $24 \%$ denied. 
Table I. Gender and residency data of the respondents, $n=179$

\begin{tabular}{llll}
\hline \multirow{2}{*}{ Variables } & & Number & Percent \\
\hline \multirow{2}{*}{ Gender } & Male & 50 & \\
& Female & 129 & 28 \\
\multirow{4}{*}{ Reside } & Hostel & 123 & 72 \\
& Out campus & 56 & 69 \\
& & & 31 \\
\hline
\end{tabular}

Table II. Stress level among individual stressor domain

\begin{tabular}{|c|c|c|c|c|c|}
\hline \multirow{2}{*}{\multicolumn{2}{|c|}{$\begin{array}{l}\text { Stressor } \\
\text { Domain }\end{array}$}} & \multicolumn{4}{|c|}{ Level of stress against individual stressor domain } \\
\hline & & $\begin{array}{l}\text { Mild } \\
(0-1.00)\end{array}$ & $\begin{array}{l}\text { Moderate } \\
(1.01-2.00)\end{array}$ & $\begin{array}{l}\text { High } \\
(2.01-3.00)\end{array}$ & $\begin{array}{l}\text { Severe } \\
(3.01-4.00)\end{array}$ \\
\hline & $\%$ & $\%$ & $\%$ & $\%$ & $\%$ \\
\hline 1 & ARS & 0 & 0.5 & 15.5 & 84 \\
\hline 2 & IRS & 2 & 15 & 27 & 56 \\
\hline 3 & TLRS & 5 & 21 & 38 & 36 \\
\hline 4 & SRS & 2 & 29 & 49 & 20 \\
\hline 5 & DRS & 33 & 26 & 23 & 18 \\
\hline 6 & GARS & 1 & 7 & 35 & 57 \\
\hline \multicolumn{2}{|c|}{ Average } & 7 & 16 & 32 & 45 \\
\hline
\end{tabular}

ARS=Academic Related Stressor, IRS=Intrapersonal and Interpersonal Related Stressor, TLRS=Teaching and Learning Related Stressor, SRS=Social Related Stressor, DRS=Drive and Desire Related Stressor, GARS=Group Activities Related Stressor.

Table III. Distribution of level of stress among the respondents

\begin{tabular}{|c|c|c|c|c|c|c|c|c|c|c|}
\hline \multicolumn{7}{|c|}{ Stress level of the respondents } & \multicolumn{4}{|c|}{ Total } \\
\hline \multirow[t]{2}{*}{ Gender } & \multicolumn{2}{|c|}{$\begin{array}{l}\text { Mild } \\
(0-1.00)\end{array}$} & \multicolumn{2}{|c|}{$\begin{array}{l}\text { Moderate } \\
(1.01-2.00)\end{array}$} & \multicolumn{2}{|c|}{$\begin{array}{l}\text { High } \\
(2.01-3.00)\end{array}$} & \multicolumn{2}{|c|}{$\begin{array}{l}\text { Severe } \\
(3.01-4.00)\end{array}$} & \multirow[t]{2}{*}{$\mathrm{n}$} & \multirow[t]{2}{*}{$\%$} \\
\hline & $n$ & $\%$ & $\mathrm{n}$ & $\%$ & $\mathrm{n}$ & $\%$ & $\mathrm{n}$ & $\%$ & & \\
\hline Male & 1 & 2 & 2 & 4 & 28 & 56 & 19 & 38 & 50 & 100 \\
\hline Female & 3 & 2 & 10 & 8 & 65 & 50 & 51 & 40 & 129 & 100 \\
\hline Total & 4 & 2 & 12 & 6 & 93 & 53 & 70 & 39 & 179 & 100 \\
\hline
\end{tabular}


Table IV. Stress level and academic performance (CGPA) of the respondents in terms of gender and residency

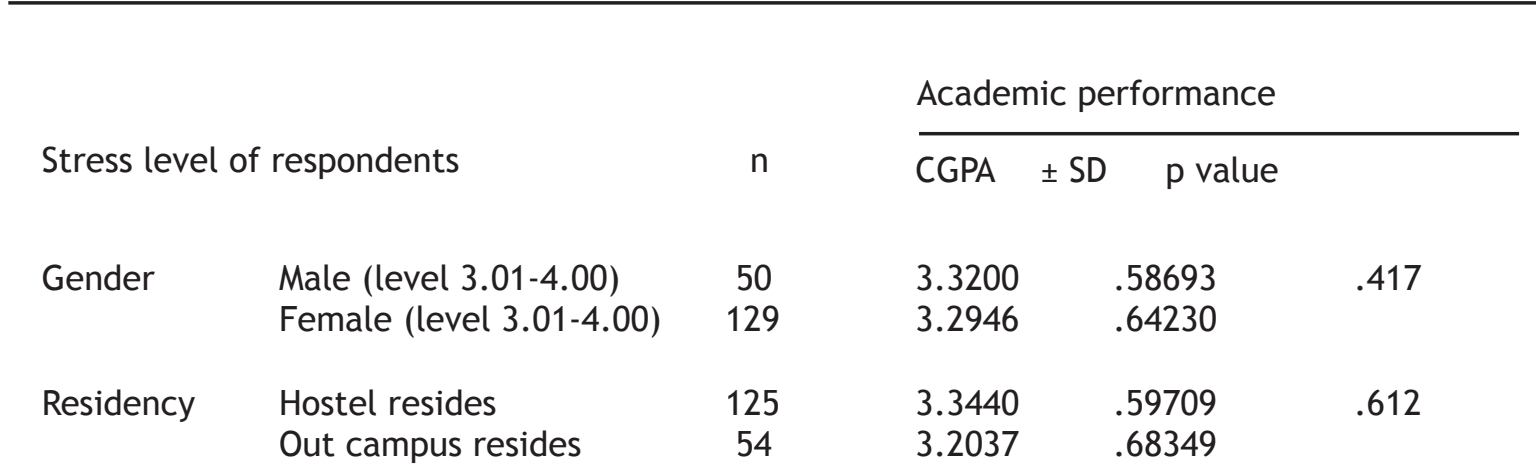

\section{DISCUSSION}

Recently stress has appeared as an emerging issue among the medical students. ${ }^{19}$ Majority of the respondents in this study were found stressful where $72 \%$ were female and $28 \%$ were male (Table I) which actually corresponded to the male-female student ratio of the university.

There were six domains of stress that were studied, which were Academic Related Stressor (ARS), Intrapersonal and Interpersonal Related Stressor (IRS), Teaching and Learning Related Stressor (TLRS), Social Related Stressor (SRS), Drive and Desire Related Stressor (DRS) and Group Activities Related Stressor (GARS). Among these domains, the stress level was severe $(84 \%)$ in the academic related stressor (ARS) domain (Table II) that specified on the educational, college, universities and student events. Medical students perceived stress, mostly due to academic related factors. Previous study showed a number of academic related stressors that included test and examinations, a big range of content to be learnt, lack of time to do the revision, poor marks, having selfexpectations to do well, insufficient skill in medical practice, falling behind in reading schedule, heavy workload, difficulty in understanding the content, and inability to answer teachers' questions. ${ }^{20-23}$ These findings have similarity with Thomas ${ }^{24}$ who reported that school examinations, school work and homework were the major stressors. Intra-Interpersonal Related Stressor (IRS) rated severe stress by $49 \%$ respondents while Social Related Stressors (SRS) rated high stress by $56 \%$ of the respondents. This could be due to besides pursuing knowledge in university; a student also gets to socialize with different kinds of people and undergo psychological development. Students faced a changing of education system, lifestyle and social environment. They now meet people of different ages and backgrounds. Thus interpersonal skills were needed to socialize with the people around them. ${ }^{18}$ Thus it was apparent that a number of factors were related to the stress level of the students. Anyway, none of the stress domains significantly affected the academic performance of the students (Table II).
The stress level among the students of this study was found higher. Majorities (53\%) were in high level stress (2.01-3.00) and 39\% were in severe level (3.01-4.00) stress. Almost equal number of male $(56 \%)$ and female $(50 \%)$ respondents experienced high level stress, and $38 \%$ and $40 \%$ experienced severe level of stress (Table III). In general, it is a common fact that life of a medical student or health profession is stressful. Mild, moderate, high or severe level of stress had been reported among the students of medical and health professions. ${ }^{17,25}$ In India the stress level was found as high as $89.64 \% .{ }^{26}$ Similarly, Muhamad, et al., ${ }^{9}$ and Miller, ${ }^{10}$ had reported a high prevalence of stress in medical students, ranging from $30 \%$ to $50 \%$. Medical students are expected to learn and master a huge amount of knowledge, attitudes and skills for which they had to work hard which in turn put them under a lot of stress. ${ }^{27}$ Knowhow of the management of stress is of up most importance.

Many past researches found a significant correlation between stress and academic achievement ${ }^{19}$ in both genders. The most common view of stress towards academic achievement was its negative relationship with academic performance. However, the present study differs; it identified that the higher and severe level stress experienced students achieved higher CGPA (more than 3 in a 5 scale) with insignificant difference between gender $(p=.417)$ and residence $(p=.612)$ of this study (Table IV). This finding has some similarity with Rafidah, et al., ${ }^{28}$ where they found that students of moderate degree stress performed to have satisfactory GPAs. They reported that the moderate stress experienced by the students is desirable for attaining good academic performance. Sanders and Lushington, ${ }^{14}$ explained in his study that stress gave negative impact on academic performance, but it was poorly related. Elias et al., ${ }^{19}$ also found that there was a significant, but weak and negative relationship between stress and academic achievement. Most importantly, the medical students those can manage the stress level well are associated with higher academic performance.

Students' perception on the impact of stress toward academic performance revealed that $76 \%$ respondents considered stress positively and agreed that stress 
motivated them for better academic performance. Linn $^{7}$ argued that stress is actually needed for learning process.

Medical students in UKM are exposed with decision making in a tough situation, breaking bad news, team building, managing diversity, spiritual development, reflective skills, interfaith discussion, joint activities with students association, movie watching with reflection, learning style, personality trait, publicly speaking, etc. through a personal and professional development module over the whole five year period. Probably, this is the reason of achieving higher CGPA even though they experienced with the higher and more severe level of stress. The important thing is to learn how to manage stress. Respondent with a high and severe level of stress are able to achieve higher CGPA and able to do well academically when they are capable to manage their stress well. This is supported by Akgun, ${ }^{16}$ which explained that the highly resourceful student manages academic stress better thus denying the effect of stress towards their academic performance. Students have to be exposed to the different ideas those meant to facilitate their lives. ${ }^{29}$

\section{CONCLUSION}

A student can be stressed due to so many stressors, such as academic reason, financial problem, health problem or loss of close family member or friend, etc. The main stressor identified in this study was academic related. There was no negative correlation between stress level and academic performances of the students. Higher academic performance can be achieved even with a higher level of stress, if the students are able to manage their stress well. It is the person's ability to face the everyday challenges that will determine whether he/she will be stressed or not. Medical schools should expose the students to various topics such as stress management, decision making in a tough situation, breaking bad news, team building, managing diversity, spiritual development, reflective skills, interfaith discussion, etc. in order to promote and produce stress free holistic confident practitioners. UKM medical students are highly resourceful to manage their academic stress better thus denying the effect of stress towards their academic performance. This paper offers other medical schools and academic planners a window or guideline for a comprehensive use of personal and professional development activities of the students to cope with the academic related matters and also to develop confidence among students for better adjustment in classroom, group and society.

\section{ACKNOWLEDGEMENT}

We would like to express our sincere thanks to the Ethics Committee of the Faculty of Medicine, Universiti Kebangsaan Malaysia for approval of this study.

\section{REFERENCES}

1. Stewart $S M$, Lam $T H$, Betson $C L$, Wong $C M$, Wongm AMP. A prospective analysis of stress and academic performance in the first two years of medical school. Med Educ 1999; 33:243-50.

2. Selye H. Stress without distress. New York: Harper \& Row, 1974.

3. Rosenham DL, Seligman ME. Abnormal psychology. 2nd ed. New York: Norton, 1989.

4. Myers DG. Stress and Health. 6th ed. In: Exploring Psychology. New York: Worth Publishers, 2005.

5. Webster New World Dictionary. 4th ed. Houghton Mifflin Harcourt, 1999.

6. Yakushko O, Watson M, Thompson S. Stress and Coping in the Lives of Recent Immigrants and Refugees: Considerations for Counseling. Int J Adv Counselling 2008; 30:167-78.

7. Franken RE. Human motivation. 3rd ed. Belmont: Brooks/Cole, 1994.

8. Linn BS, Zeppa R. Stress in junior medical students: relationship to personality and performance. J Med Educ 1984; 59:7-12.

9. Muhamad SBY, Ahmad FAR, Yaacob MJ. Prevalence and sources of stress among medical students in Universiti Sains Malaysia. Medical Education: Universiti Sains Malaysia (USM), 2009. [unpublished]

10. Miller PM, Surtees PG. Psychological symptoms and their course in first-year medical students as assessed by the Interval General Health Question naire (I-GHQ). Br J Psychiatry 1991; 159:199-207.

11. Elliot AJ, Shell MM, Henry KB, Maeir MA. Achieve ment goals, performance contingencies, and performance attainment: An experimental test. Journal of Educational Psychology 2005; 97:63040.

12. Choi YB, Abbott TA, Arthur MA, Hill D. Towards a failure wireless classroom paradigm. International Journal of Innovation and learning 2007; 4:14-25.

13. Bennett R. Determinants of undergraduate student dropout rates in a university business studies department. Journal of Further and Higher Education 2003; 27:123-41.

14. Sanders AE, Lushington K. Effect of perceived stress on students' performance in dental school. Journal of Dental Education 2002; 66:75-81.

15. Misra R, McKean M. College students' academic stress and its relation to their anxiety, time management, and leisure satisfaction. American Journal of Health Studies 2000; 16:41-51.

16. Akgun S, Ciarrochi J. Learned resourcefulness moderates the relationship between academic stress and academic performance. Educational Psychology 2003; 23:287-94.

17. Shah M, Hassan S, Malik S, Sreeramaredd CT. Perceived stress, sources and severity of stress among medical undergraduates in a Pakistani medical school. BMC Med Educ 2010; 10:1-8.

18. Yusoff MSB, Ahmad Fuad AR. Medical Student Stressor Questionnaire (MSSQ) manual. KKMED publications. 2010. Medical Education 
Department, USM, Kubang Kerian. Kelantan, Malaysia. [unpublished]

19. Elias H, Ping WS, Abdullah MC. Stress and academic achievement among undergraduate students in Universiti Putra Malaysia. Procedia Social and Behavioral Science 2011; 29:646-55.

20. Yusoff MSB, Yen YL, Heng WL, et al. A study on stress, stressors and coping strategies among Malaysian medical students. International Journal of Students' Research 2011; 1:45-50.

21. Yusoff MSB, Ahmad Fuad AR, Yaacob MJ. Prevalence and sources of stress among Universiti Sains Malaysia Medical Students. Malays J Med Sci 2010; 17:30-7.

22. Yusoff MSB, Ahmad Fuad AR. Prevalence and sources of stress among postgraduate medical trainees: initial findings. ASEAN Journal of Psychiatry 2010; 11. Available at: http://www. aseanjournalofpsychiatry.org/oe11206.htm. Accessed 20 April 2012.

23. Yusoff MSB, Saiful M, Ahmad Fuad AR, Mohd Jamil $Y$. The prevalence of final year medical students with depressive symptoms and its contributing factors. International Medical Journal 2011; 18:305-9.

24. Thomas E. Adolescent stress and management strategies: some lessons for schooling and society. Singapore Journal of Education 1988; 9:55-66.

25. Lapane KL, Hughes $C M$. Job satisfaction and stress among pharmacists in the long-term care sector. Consult Pharm 2006; 21:287-92.

26. Mannapur B, Dorle AS, Hiremath ID, et al. A study of psycological stress in undergraduate medical students at SN Medical College, Bagalkot, Karnataka. Journal of Clinical and Diagnostic Research 2010; 4:2869-74.

27. Wolf TM, Kissling GE. Changes in life-style charac teristics, health and mood of freshman medical students. J Med Edu 1984; 59:806-14.

28. Rafidah K, Azizah A, Norzaidi MD, Chong SC, Salwani MI, Noraini A. Stress and academic performance: empirical evidence from university students. Academy of Educational Leadership Journal 2009; 13:37-51.

29. Nor Afiah MZ, Rahmah MA, Salmiah MS, Fazilah I, Shamsul Azhar S. Religious personality and smoking among form two students in rural schools in Malacca, Malaysia. International Medical Journal Malaysia 2012; 11:39-44. 